\title{
DENTAL EVIDENCE FOR WILD TUBER PROCESSING AMONG TITICACA BASIN FORAGERS 7000 YBP
}

James T. Watson ${ }^{1,2}$ and Randall Haas ${ }^{3,4}$

${ }^{1}$ Arizona State Museum, University of Arizona, Tucson, AZ 85721

${ }^{2}$ School of Anthropology, University of Arizona, Tucson, AZ 85721

${ }^{3}$ Department of Anthropology, University of California, Davis, CA 95616

${ }^{4}$ Collasuyo Archaeological Research Institute, Puno, Peru

14 pages including cover page, abstract and text, 6 pages of literature cited, one page with figure captions, 7 figures, 5 tables

Abbreviated title: Dental wear among Titicaca Basin foragers 7KYBP

Key words: tooth wear, foraging, LSAMAT, tuber processing, Andes

James T. Watson, Arizona State Museum, University of Arizona, PO Box 210026, Tucson, AZ 85721, (520) 621-4794, (520) 621-2976 (fax), watsonjt@email.arizona.edu

Randall Haas, Department of Anthropology, University of California, 328 Young Hall, One Shields Ave., Davis, CA 95616, (530) 752-0745, whaas@gmail.com

Grant sponsorship: NSF DDIG \# BCS-1311626, APS Lewis \& Clark Fund, The University of Arizona 


\begin{abstract}
Objectives. The objective of this work is to characterize dental wear in a skeletal sample dating to the Middle/Late Archaic period transition (8000-6700 cal. B.P.) from the Lake Titicaca Basin, Peru to better define subsistence behaviors of foragers prior to incipient sedentism and food production.

Materials and Methods. The dental sample consists of 251 teeth from 11 individuals recovered from the site of Soro Mik'aya Patjxa (SMP), the earliest securely dated burial assemblage in the Lake Titicaca Basin and the only burial assemblage in the region from an unequivocal forager context. Occlusal surface wear was quantified according to Smith (1984) and Scott (1979) to characterize diversity within the site and to facilitate comparison with other foraging groups worldwide. General linear modeling was used to assess observation error and principal axis analysis was used to compare molar wear rates and angles. Teeth were also examined for caries and specialized wear.

Results. Occlusal surface attrition is generally heavy across the dental arcade and tends to be flat among posterior teeth. Only one carious lesion was observed. Five of the 11 individuals exhibit lingual surface attrition of the maxillary anterior teeth (LSAMAT).

Discussion. Tooth wear rates, molar wear plane, and caries rates are consistent with terrestrial foraging and a diverse diet. The presence of LSAMAT indicates tuber processing. The results therefore contribute critical new data toward our understanding of forager diet in the Altiplano prior to plant and animal domestication in the south-central Andes.
\end{abstract}


The south-central Andes of Peru and Bolivia is one of few regions in the world where the domestication of native plants and animals is suspected to have occurred endogenously (Pearsall, 1992; Price and Gebauer, 1995; Smith, 1995). More than 6000 years after foragers colonized the high-elevation Altiplano region, forager economies gave way to incipient agro-pastoralism during the Terminal Archaic Period between approximately 5000 and 3500 cal. BP (Aldenderfer, 1989a; Bruno, 2006; Craig, 2011; Rumold and Aldenderfer, 2016). While the dietary patterns of the Terminal Archaic Period and subsequent Formative and Tiwanaku periods are anchored by empirical observations (Bandy, 2006; Browman, 1981; Hastorf, 2008; Kolata, 1993; Stanish, 2001, 2003), relatively little empirical data exist for the preceding Early to Late Archaic periods (11,000-5000 cal. BP).

Several archaeological surveys have informed inferences about broad-scale settlement patterns during the Archaic (Cipolla, 2005; Craig, 2011; Klink, 2005; La Favre, 2011), but excavated cultural features with absolute dates from the Archaic periods are restricted to only five sites including Qillqatani (Aldenderfer, 1989b, 2005; Eisentraut, 1998), Jiskairumoko (Craig, 2011), Kaillachuro (Craig, 2011), Muruqulla (Juengst, Chávez, Hutchinson, and Chávez, 2016), and Soro Mik'aya Patjxa (Haas and Viviano Llave, 2015). While features from the other four sites date to the Terminal Archaic Period, features from Soro Mik'aya Patjxa (SMP) date to the Middle/Late Archaic transition (7000 cal. BP; Fig. 1). Soro Mik'aya Patjxa therefore offers a unique empirical window into forager economies of the Lake Titicaca Basin (LTB).

\section{[Figure 1 here]}

In this study, we seek to characterize diet of the residents at Soro Mik'aya Patjxa through a multi-dimensional analysis of dental wear patterns. The study constitutes just one of several lines of evidence for LTB forager diet and represents the first concerted effort to explore their diet through dental wear patterns. The sample includes 251 permanent teeth from 11 human individuals recovered from recent excavations at SMP (Haas and Viviano Llave, 2015).

Numerous environmental and behavioral factors affect tooth wear across human groups. These include climate and local ecology (Scott and Winn, 2011; Walker and Erlandson, 1986; Watson, Arriaza, Standen, and Munoz Ovalle, 2013), subsistence practices and dietary composition (Cohen and Armelagos, 1984; Littleton and Frohlich, 1993; Molnar, 1971; Smith, 1984), non-masticatory oral behaviors and functional occlusion (Kaidonis, Ranjitkar, Lekkas, Brook, and Townsend, 2014; Kieser et al., 2001; Milner and Larsen, 1991), food behaviors and food processing (Mølleson, Jones, and Jones, 1993; Pechenkina, Benfer, and Zhijun, 2002; Sciulli, 1997), oral hygiene and disease prevalence (Eshed, Gopher, and Hershkovitz, 2006; Hillson, 2002; Molnar, 2008), inheritance and susceptibility (Harryparsad, Rahman, and Bunn, 2013; Kaidonis, Richards, Townsend, and Tansley, 1988; Lucas et al., 2013), and age and sex (Berbesque et al., 2012; Fujita and Ogura, 2009; Lovejoy, 1985; Lukacs, 2008). Patterns of tooth wear therefore provide an important tool for anthropologists to interpret human adaptation, behavior, and biocultural processes impacting past populations (Kaidonis et al., 2014; Molnar, 1971).

Tooth wear is a multifactorial process that results from three main interacting mechanisms: attrition, abrasion, and erosion (Hillson, 2002; Kaidonis et al., 1988; Miles, 2001). Attrition is caused by wear of the tooth surface through friction resulting from tooth-on-tooth contact (Hillson, 2002; Kaidonis et al., 2014; Lukacs, 1992). A critical element contributing to this process is occlusion and masticatory loading (Kaidonis et al., 2014). Abrasion is the loss of 
surface detail from friction with exogenous material such as the presence of foreign abrasives (Hillson, 2002; Kaidonis et al., 1988). Erosion is the reduction of dental surfaces due to nonbacterial exogenous or endogenous chemical substances (Kieser et al., 2001). Each of these processes is continuous, unidirectional, and age-progressive (Brothwell, 1989; Hillson, 2002; Miles, 2001).

Several studies have successfully correlated differences in the rates and patterns of these wear processes to differences in overall subsistence practices among preindustrial populations, where occlusal wear is generally severe (Deter, 2009; Fujita and Ogura, 2009; Kaifu, 1999; Kieser et al., 2001; Larsen, 2015; Liu, Zhang, Wu, and Zhu, 2010; Molnar, 1971; Smith, 1984). Additional factors such as tooth form and structure, occlusal relationships, enamel quality, and cultural activities (such as the use of teeth as tools) also play an important role in the differential destruction of dental tissues with various diets (Kaidonis et al., 2014; Kieser et al., 2001; Milner and Larsen, 1991; Molnar and Molnar, 1990; Sciulli, 1997). However, dietary composition and food processing methods (both affecting food consistency) have the greatest effect upon the macroscopic patterns of occlusal surface wear observed in archaeological samples (Chattah and Smith, 2006; Larsen, 1981; Molnar, 1971; Pechenkina et al., 2002; Scott, 1979a, 1979b; Smith, 1984; Smith, 1972; Watson, 2008b; Watson et al., 2013).

Occlusal surface wear of terrestrial foragers is generally heavy and relatively flat across the entire dental arcade. This is exhibited as increasing exposure of the underlying dentin from adolescence through senescence (Deter, 2009; Larsen, 2015; Molnar, 1971). The degree of wear on each dental member is largely dependent upon its timing of eruption into occlusion (Hillson, 2002). However, several authors also note heavier wear across the anterior teeth among foraging populations, which is often attributed to differential loadings associated with habitual application of heavy forces due to non-masticatory use of the front teeth, such as for tools or for grasping (Clement and Hillson, 2012; Clement, Hillson, and Aiello, 2012; Littleton, Scott, McFarlane, and Walshe, 2013; Mayhall and Kanazawa, 1989; Miles, 2001; Molnar, 2008; Reinhardt, 1983).

Sciulli (1997) identified three 'dental cultural ecological environments' based on a study of temporal patterns of tooth wear (and dental pathology) among 40 prehistoric samples from the upper Ohio River Valley. He described: 1) high rates of wear and low frequencies of pathology among Late Archaic foragers, 2) low rates of wear and low frequencies of pathology among Woodland forgers after the introduction of pottery, and 3) low rates of wear and high frequencies of pathology among Late Prehistoric agriculturalists. Other studies document differences in the degree of wear (Molnar, 1971) or percentage of dentin exposure (Deter, 2009) between distant groups of foragers versus agriculturalists and document that foraging groups display faster rates or heavier wear than their agriculturalist counterparts consistently. For example, Deter's (2009) study of prehistoric Native American samples from the Ohio River valley (foragers) and the American Southwest (agriculturalists) reveal that dentin exposure increased from $27 \%$ to $85 \%$ from young to old adult groups among foragers, compared to increases from $18.5 \%$ to $45 \%$ over the same age groups among the agricultural sample.

Most researchers agree that patterns of heavier wear among foragers result from a combination of factors, the most influential of which are the consumption of a wider variety of less processed foods, and of tough, fibrous diets that required more powerful chewing and extensive lateral movements of the jaw. Reinhardt (1983) has shown that dietary consistency produces forces on the dental arcade that is sufficient to create zero to negative overjet (overbite) in groups exhibiting heavy attrition. In contrast, increased levels (or complexity) of food processing associated with agro-pastoral economies, from stone grinding grains to boiling 
foodstuffs in pottery vessels, significantly reduces food consistency, thereby resulting in more direct tooth-on-tooth contact during mastication. Such reduced masticatory loading results in slower wear rates, but at the same time leads to more uneven wear.

The angle (or plane) of wear across the occlusal surface also differs between skeletal samples of diverse subsistence economies to a measurable extent (Chattah and Smith, 2006; Molnar, 1971; Pechenkina et al., 2002; Smith, 1984; Watson, 2008). Occlusal wear angle in the molar region is shaped by differential wear of the buccal and lingual cusps (Hillson, 2002; Reinhardt, 1983). With progressive wear, steeper occlusal angles develop from lingual to buccal in mandibular molars, and buccal to lingual in maxillary molars. Each subsequent molar within an arcade expresses steeper wear angles along the order of eruption sequence, eventually resulting in a reversed curve of Monson (Osborn, 1984). This pattern becomes more apparent in agricultural groups where the consumption of a diet of narrow breadth and more extensive premasticatory processing reduces chewing resistance and lateral movements, thereby increasing the amount of contact between cusps and creating steeper occlusal angles at faster rates (Smith, 1984). In a global archaeological sample of five forager groups $(\mathrm{N}=298)$ and five early agricultural groups $(\mathrm{N}=365)$ Smith (1984) documented that foragers generally display flatter molar wear angles $(b=0.4)$ relative to agriculturalists who display more angled molar surfaces $(b=1.4)$. In addition, the rates of change of these angles by wear stage were found to be higher among agriculturalists $\left(3.4-5.3^{\circ}\right.$ per wear stage) than among foragers $\left(1.9-3.5^{\circ}\right)$.

Because previous research points to the south-central Andes as a potential center of tuber and Chenopodium domestication during the Terminal Archaic Period, we might expect the earlier forager populations of the region's Middle and Late Archaic periods (9000-5000 cal. BP) to exhibit both material and dental correlates of a forager economy. Preliminary analyses of Middle and Late Archaic settlement patterns and SMP artifacts and features have yielded evidence consistent with these expectations. The lack of investment in long-term housing or ceramic technology suggests a high degree of residential mobility and an emphasis upon the procurement of wild resources (Cipolla, 2005; Craig, 2011; Haas and Viviano Llave, 2015; Klink, 2005). Abundant but informal groundstone technology and subterranean storage features suggest intensive plant processing with formal attributes of the groundstone technology pointing to tuber processing (Haas and Viviano Llave, 2015; Rumold and Aldenderfer, 2016).

Given previous research on dental wear patterns and archaeological observations at SMP, we derive three general expectations for this analysis of dental wear among the Middle/Late Archaic individuals recovered from SMP. First, as terrestrial foragers consuming tough and fibrous wild foods, tooth wear should be heavy overall and occur at a faster rate over the lifecourse than among preindustrial agriculturalists. Second, given the evidence for plant food processing and intensification use of plant foods at SMP, we expect to observe relatively flat occlusal surface wear compared to samples of dedicated agriculturalists worldwide. Finally, we expect a low incidence of dental caries due to consumption of a low-sugar, wild-resource diet, but may see some tooth loss due to heavy wear, exposure of the pulp chamber, and evulsion. In the analysis of SMP dentition that follows, we find that occlusal wear rate, angulation, low caries presence, and tooth loss among older individuals to be consistent with these expectations. In addition, we make an unanticipated observation of lingual surface attrition of the maxillary anterior teeth (LSAMAT) - the occurrence of which likely indicates tuber processing - and unique wear on the cervical surfaces of the mandibular anterior teeth. 


\section{MATERIALS AND METHODS}

We examined 251 permanent teeth present in 11 out of 16 individuals recovered in 2013 from the site of Soro Mik'aya Patjxa (Fig. 2; Table 1). SMP is an open-air site located in Altiplano grasslands of the western Titicaca Basin some $30 \mathrm{~km}$ west of the modern shoreline of Lake Titicaca (see Fig. 1). Seventeen radiocarbon assays from burial and non-burial pit-feature contexts range from 8000 to $6700 \mathrm{cal}$. BP with most dating to the younger Late Archaic end of the range (Haas and Viviano Llave, 2015). As such, it appears that the occupation of SMP occurred more than 1500 years before the posited onset of low-level food production around 5000 cal. BP.

[Figure 2 here]

[Table 1 here]

Most of the skeletal elements present were in good condition thereby facilitating reliable estimations of age and sex for most individuals. The remainder of the skeletal sample was poorly preserved limiting dental and demographic observations. Age at death for the 11 individuals included in this analysis was estimated using a combination of dental eruption (after Ubelaker, 1989), epiphyseal fusion, cranial suture closure, and macroscopic degenerative changes in the pubic symphysis following standards described in Buikstra and Ubelaker (1994). The sample was classified into four ordinal cohorts $(10-19 ; 20-29 ; 30-39 ; 40-49)$. The modal age at death occurred at some point during the fourth decade of life; however, infants and young juveniles are under-represented, likely due to preservation bias.

To test our expectations that the individuals recovered from SMP consumed a forager diet, we conducted four analyses on the sample to characterize dental wear and decay, including: (1) absolute and relative degree of occlusal surface wear for all teeth, (2) rate of molar wear, (3) angle of molar wear, and (4) occurrence of dental caries and antemortem tooth loss (AMTL). Additional qualitative observations relevant to dietary behavior were made as encountered.

1. Occlusal surface wear. Occlusal surface wear was scored using the eight-point ordinal scale defined by Smith (1984) for both adult arcades (maxillary and mandibular). The degree of absolute occlusal surface wear was compared for each tooth across an age gradient by generalized linear modeling (GLM) analysis (Gill, 2001) as outlined by Pechenkina et al. (2002) to determine whether gross differences in wear exist across the dentition and to identify if wear exhibits significant covariance with age.

The degree of relative occlusal surface wear was measured by comparing wear scores in all teeth relative to the wear score of the first molar in each jaw (e.g., LI1/LM1*100) to control for the timing and sequence of eruption (Clement and Hillson, 2012; Littleton et al., 2013). Clement and Hillson (2012) measured the percentage of dentin exposure of teeth and referred to this as the "wear ratio" as it reflects the effect that eruption sequence has on exposure to wear. Since the first molar is generally the first permanent tooth to erupt, teeth with similar wear to the first molar will have a wear approaching $100 \%$, while teeth with greater wear will have wear ratios greater than $100 \%$, and teeth with less wear will have wear ratios less than $100 \%$. We followed the method of Littleton and colleagues (2013) to develop "standardized wear scores" using ordinal scores from Smith (1984). Standardized wear scores are compared using t-tests for independent samples. 
2. Molar wear rate. Occlusal wear was also scored on each quadrant of the molar surface using the ten-point ordinal scale developed by Scott (1979a). In this method, each of the four molar surface quadrants is given a wear score ranging between 1 (minimal) and 10 (complete) based on relative enamel loss. Scores for all four quadrants are added to give the overall wear score for the tooth, ranging from 4 to 40 . The rate of occlusal surface wear was calculated from paired first (M1) and second (M2) mandibular molars using the ratio of attrition scores (M2/M1). Following Scott (1979b), total wear scores were compared between paired molars using principal axis analysis to quantify the rate of wear across the age gradient of molar eruption. This test is designed to measure the velocity of occlusal surface wear of the molars and to provide a comparative scale for measuring the velocity of molar wear on average between samples. Scott (1979b) suggests that steeper principal axis slopes indicate more rapid rates of wear with rates generally being higher among foragers $(b>1.0)$ relative to agriculturalists $(b<1.0)$.

3. Molar wear angle. Molar wear scores obtained from the Scott (1979a) system were also used to contrast wear on the buccal cusps of the first molar (M1) and the lingual cusps of the second molar (M2) using principal axis analysis following the procedure of Chattah and Smith (2006) to determine how the angle of occlusal wear differs. This test is designed to measure the angle of occlusal surface wear present on the molars. As such this method is a further modification of Scott's (1979b) approach and employs the difference in wear based on the order and timing of eruption between M1 and M2 and the development of the 'helicoidal plane' (Osborn, 1984). An average six-year difference in eruption between the first and second permanent molars causes more wear on the first molar. In addition, normal occlusion results in faster wear on the buccal cusps of the mandibular teeth and the lingual cusps of the maxillary teeth. The M1buccal/M2lingual relationship reflects the greatest and least expressions of wear across this temporal and occlusal gradient. Therefore, greater principal axis slopes $(b)$ indicate steeper wear plane angles across the molars.

Principal axis analysis was employed in the last two analyses because it does not assume a causal relationship between variables and does not assume that the X-axis is uniformly measured without error (Chattah and Smith, 2006; Scott, 1979b). Bivariate normality ( $p>0.10)$ was found within the sample. The principal axis equation was determined by plotting the wear score of M1 on the Y-axis, and M2 on the X-axis for wear rate, and by plotting the wear score of the M1 buccal surface on the Y-axis, and M2 lingual surface on the X-axis for wear angle. Following Scott (1979b), bivariate plots of the data were prepared and all statistical tests were performed using the SPSS Ver. 24.0 for Windows.

4. Dental caries and tooth loss. All teeth were inspected for dental caries. The number, nature, and location of carious lesions were recorded per tooth following Moore and Corbett (1971). Carious lesions were identified macroscopically with a dental probe and magnifying glass. Previous research suggests that foraging populations have low caries rates $(0-5 \%)$ relative to agricultural populations (5-30\%) (Larsen, 2015; Turner, 1979). All alveolar segments were scored for antemortem tooth loss (AMTL) if the alveolar crest was undamaged and displayed partial or complete remodeling (resorption). Antemortem tooth loss has numerous etiologies and can result from extreme attrition, caries, trauma, and periodontal disease (Hillson, 2002). Tooth loss can have a significant impact on occlusal wear patterns reducing or significantly altering wear on occluding teeth or causing heavier wear on antimere dentition to compensate for missing chewing surfaces. 


\section{RESULTS}

\section{Occlusal surface wear}

Table 2 summarizes mean absolute wear scores for both jaws across age grades from the SMP sample and the results of the general linear modeling analysis. The GLM slopes of all but the second and third molars are positive, ranging from .333 to 1.333 and represent nonsignificant departures from zero. GLM slopes for upper and lower second and third molars are negative and both third molars represent significant departures from zero, which reflects the eruption sequence and absolute time in occlusion. These results therefore identify heavy wear across the dental arcade from M1 (left) to M1 (right) in the SMP sample. Most individuals experienced significant reduction in the enamel crown by the forth decade of life (30-39). As is clear from Figure 3, the greatest increase in wear occurred between the third (20-29) and fourth decades of life (30-39), eventually resulting in the complete loss of the crown among older adults (40-49). Mean change in average scores between age classes are as follows: 1.39 between juvenile and young adult, 1.83 between young and middle adult, and 1.02 between middle and old adult. These changes in wear across age classes would be even greater if the second and third molars (which experienced considerably less wear) were removed from the calculations and demonstrate that absolute wear was considerable across most of the dental arcade in both jaws.

[Table 2 here]

[Figure 3 here]

Table 3 and Figure 4 summarize relative wear and the results of standardized wear scores comparisons. As observed with the absolute wear, except for the second and third molars, occlusal surface wear is significant among all teeth compared to the first molar in both jaws. The greatest (statistically significant) relative wear is present on the lower incisors and canine, followed by nearly (statistically) significant wear on the upper incisors. Wear was less pronounced on the premolars and, except for UP4, did not differ significantly from the first molar indicating a faster rate of wear on average (given eruption sequence). Considerably less wear on the second and third molars respectively again reflects individual timing to eruption.

Despite the small sample size, the pattern observed here is indicative of substantial tooth wear during the Late Archaic period in the Titicaca Basin. Results from the generalized linear models identify that tooth wear was similar over much of the dental arch across age groups. These trends are mirrored in patterns of relative wear, whereby there is considerably greater wear in the anterior teeth, fast wear in the canines and premolars (resulting in similar crown loss to the first molar), and progressively less wear on the posterior molars. Smith (1984) noted this same phenomenon in her global study of tooth wear and is to be expected given the sequentially delayed timing of eruption into occlusion for the second and third molars. Hence, the heavy wear observed in the SMP sample is consistent with occlusal wear rates observed among other samples of terrestrial foragers.

[Table 3 here]

[Figure 4 here]

Molar wear rate 
Table 4 and Figure 5 display the results of the principal axis analysis on paired mandibular molar wear scores which reveal a moderately steep slope $(b=0.718)$. This pattern approaches that observed by Scott (1979b) for foragers from the Indian Knoll site in Kentucky but falls short of the slope expected for terrestrial foragers (i.e., $b>1.0$ ). Mean molar wear is absolutely greater, but the overall wear rate is closer to that observed by Scott (1979b) among Late Mississippian agriculturalists (the Hardin and Campbell sites). These results demonstrate that wear rate was relatively slower on the posterior teeth than observed on the anterior teeth in the preceding analyses.

[Table 4 here]

[Figure 5 here]

\section{Molar wear angle}

Table 4 and Figure 5 also display the results of the principal axis analysis on paired mandibular M1 buccal cusps and M2 lingual cusps which reveal a low slope value $(b=0.551)$ indicative of generally shallow occlusal wear angles. This pattern falls very close to the slopes observed by Smith (1984) among terrestrial foragers $(b=0.4)$ and supports our expectations of roughly flat wear associated with a terrestrial foraging diet.

\section{Molar wear comparisons}

Similar analyses of molar wear rate and angle conducted on archaeological samples associated with differing subsistence regimes provide some comparative data to further contextualize the SMP results (Table 5). Comparative data, using methods developed by Chattah and Smith (2006), include coastal foragers from northwest Chile (CHN: Chinchorro) (Watson et al., 2013), mixed subsistence groups from northwest Mexico (LPA: La Playa) (Watson, 2008) and northwest Chile (AZP: Azapa) (Watson et al., 2013), and farmers from the Levantine Chalcolithic (LC1: Wadi Makkukh and LC2: Peqi'in) (Chattah and Smith, 2006). Table 5 demonstrates a steady trend in molar wear rate (M1/M2) across subsistence categories from shallow slopes and higher $\mathrm{Y}$-intercepts among the foraging samples to steeper slopes and lower Y-intercepts among farmers. This pattern is the inverse of that observed by Scott (1979b) in the Ohio River Valley samples with farmers displaying slopes greater than one. Of course local environmental or behavioral circumstances could play a significant role between these geographically disparate samples, but the comparative samples all originate from arid environments and demonstrate closer similarities within subsistence categories than across them. A similar trend is present in molar wear angle (M1buc/M2ling) across subsistence categories whereby angles are flatter among the foraging samples and steeper among farmers.

These patterns are very similar to what Smith (1984) observed in her global sample of foragers and farmers. Although the methods used to produce the occlusal wear slopes differ between Smith (1984) and Chattah and Smith (2006), the relative relationships of the slopes across economic populations are the same. Smith (1984) measured actual molar wear on a single molar with a modified protractor reflecting the degree of buccal-lingual angulation. Chattah and Smith (2006) compare ordinal wear scores on M1 buccal cusps to those on M2 lingual cusps, reflecting the maximum and minimum expressions of wear between these teeth across an 
approximate six-year interval difference. Both methods compare rates of wear between molar buccal and lingual cusps. Although these measures are not directly comparable (degrees vs. ratio), relationships of values are comparable when plotted across samples with different subsistence regimes. Both methods demonstrate flatter molar wear (flatter slope) among foragers and steeper angulation among agriculturalists (steeper slope).

Figure 6 demonstrates how the comparative samples cluster closely together by subsistence category when plotted by slope and Y-intercept. The sum of these comparisons demonstrates that both wear rate and angle is similar by subsistence and supports our expectations that molar wear at SMP is associated with a foraging diet.

[Table 5 here]

[Figure 6 here]

\section{Dental caries and tooth loss}

Examination of all of 251 teeth in the SMP sample (Table 1) revealed only a single carious lesion thereby yielding a caries rate of $0.3 \%$ ( $0.6 \%$ of posterior teeth), which is consistent with a forager pattern (Lanfranco and Eggers, 2010; Turner, 1979). The lesion was located on the right mandibular first molar of a middle-to-older adult (35-45) male who had also lost the left mandibular first and second molars antemortem. The carious lesion was a large cavity that likely led to an infection of the pulp chamber and the development of a pair of active abscesses (draining buccal and lingual). Wear was extreme on the molar, suggesting that the lesion was likely a secondary infection resulting from exposure of the pulp cavity due to heavy attrition. This could have also contributed to the loss of the molars on the left side of the jaw. The remaining molars with extreme wear (near or complete crown loss), however, exhibited secondary dentin overlaying the pulp cavity.

Four out of the eleven individuals examined from the SMP sample had evidence for antemortem tooth loss, consisting of 14 out of 220 observable alveolar segments $(3.4 \%)$. In nearly every case, these were the oldest individuals in the sample and presented heavy tooth wear, often resulting in exposed pulp chambers. Given the single carious lesion observed in the sample (also associated with heavy occlusal surface wear), it is likely that most — if not all —of the tooth loss observed at SMP resulted from exposure of the pulp chamber from heavy wear, the direct development of infection in the pulp chamber, and eventual evulsion of the tooth.

\section{LSAMAT}

An unanticipated, but informative, observation in the SMP dentition includes five of the 11 individuals exhibiting lingual surface attrition of the maxillary anterior teeth (LSAMAT) (Turner and Machado, 1983). Those individuals affected include three adult females, one adult male, and one adolescent (Table 1; Fig. 7). This was generally characterized by a steep, lingually-inclined angle of wear on the anterior teeth that led to extensive exposure of dentin on the lingual surface of both central and lateral incisors, and similarly inclined wear (albeit with less dentin exposure) on the canines. The pattern was unobservable in the remaining individuals due to missing teeth or heavy wear (removal of the crown). Therefore, the frequency of individuals exhibiting this trait suggests that it was not anomalous but instead reflects a common behavior among the SMP foragers. Following Turner and Machado (1983), we suggest that the 
observed LSAMAT among these Late Archaic inhabitants of the Altiplano reflects intensive use of the maxillary anterior teeth for processing tubers - an interpretation that we discuss at greater length below.

\section{Cervical wear on the mandibular anterior teeth}

A second unanticipated observation was the presence of three individuals (out of seven observable) exhibiting wear across the cervical area and proximal roots of the anterior mandibular teeth (Fig. 7). This is often referred to as non-carious cervical lesions (NCCL) in the clinical literature and can result from chemical dissolution of the cementum and dentin producing a marked cupping at these locations (Kaidonis, 2008). However, there are several processes at work in the cases observed from SMP. Based on examination under magnification (hand lens), there appears to be evidence of both erosion and abrasion contributing to the wear of the anterior cervical surfaces. In addition, periodontal tissues had to have receded to expose the roots to wear. Unfortunately, these cervical lesions also experienced some postmortem taphonomic alterations that partially obscured our observations.

Abrasion and erosion, in addition to attrition, play an important role in the differential destruction of tooth surfaces with varying diets (Kieser et al., 2001). In addition, the three individuals exhibiting cervical wear on the mandibular anterior teeth also display LSAMAT, possibly indicating a link between these distinctive wear patterns and the processing of tubers. Alternatively, such wear could have been caused by placing quids between the lips and gums and/or particularly erosive agents in the diet. We currently lack a theoretical model for interpreting this pattern; however, we discuss a potential mechanism for these observations below.

[Figure 7 here]

\section{DISCUSSION}

The overall dental wear observed in the SMP sample is consistent with patterns observed among other archaeological samples of terrestrial foraging populations (Deter, 2009; Fujita and Ogura, 2009; Kieser et al., 2001; Smith, 1984). The rapid rates of crown loss and flat molar wear are common to terrestrial foragers who consumed a diet that involved minimal processing and tough fibrous foods. The lack of carious lesions is also consistent with the consumption of such a diet.

These results support the hypothesis that occlusal surfaces among members of the SMP sample should exhibit heavy wear and low angulation on the molars related to a forager diet during the Middle/Late Archaic Period in the Lake Titicaca Basin. Both absolute and relative wear was greater on anterior teeth than posterior teeth in the SMP sample and resembles dedicated foraging groups such as Australian Aborigines and Inuit (Clement and Hillson, 2012; Littleton et al., 2013). Molar wear rates and angle were similar to those observed in Smith's (1984) global sample of foragers. Smith (citing Taylor, 1963:99) attributed this general pattern to the relatively high degree of 'puncture-crushing' required for mastication of tough fibrous foods, which result in limited direct tooth-tooth contact during mastication. This subsequently influences "...the obliquity of the wear plane angle" (Smith, 1984:40) by reducing differential wear of the buccal and lingual cusps. 
One of the primary reasons for variation among foraging groups could be attributed to variation in plant consumption and processing techniques, specifically the use of grinding stone technology. The Eskimo diet, for example, is largely devoid of plant resources, being composed primarily of large quantities of tough raw, frozen, and dried meat (Smith, 1984). In contrast, the aboriginal individuals from Australia used grinding stones to process grass seeds, which were formed into hard cakes that have a similar heavy wear effect on the dentition (Smith, 1984:41).

Flat molar wear is also consistent with other observations at SMP that suggest the consumption of a varied foraging diet (Haas and Viviano Llave, 2015). Projectile points and large-bodied animal remains are abundant, suggesting substantial investment in hunting. At the same time, informal ground stone and storage pit features indicate the processing of plant food. The lack of ceramics and substantial housing suggests high degrees of residential mobility. The differences in consistency among dissimilar classes of plant and animal resources may play a significant role in observed trends in dental wear across foraging groups. In addition, although grinding technology plays a large part in reducing food consistency, cooking associated with ceramic technology is the likely primary contributing factor to the transition from abrasiondominated to attrition-dominated tooth wear patterns (Sciulli, 1997).

The evidence for differential loading of the anterior teeth in the SMP sample is also frequently observed among foraging groups, although it is usually attributed to non-masticatory use of the front teeth, such as grasping fibers or working skins (Clement et al., 2012; Deter, 2009; Kaifu, 1999; Milner and Larsen, 1991; Molnar, 1971; Reinhardt, 1983). Several individuals in the SMP sample specifically display lingual surface attrition on the maxillary anterior teeth (Turner and Machado, 1983). This is definitive evidence for specialized use-wear on the anterior teeth, but it appears to be dissimilar in nature from that recorded in other foraging groups in which wear is generally characterized as flat across the anterior dentition or inclined slightly to the labial aspect (Clement et al., 2012; Kaifu, 1999; Reinhardt, 1983).

Turner and Machado (1983) first documented LSAMAT in a skeletal sample of Archaic period (4200-3000 BP) coastal foragers from Brazil and suggested that such wear “...resulted from the continued use of the upper teeth and tongue to shred or peel abrasive plant matter for dietary or industrial or both purposes" (Turner and Machado, 1983:128). They argue that among this population, processing manioc was likely responsible for both LSAMAT and high caries rates. LSAMAT has since been recognized in several other skeletal samples across the world (Da-Gloria and Larsen, 2014; Harper and Fox, 2008; Hartnady and Rose, 1991; Irish and Turner, 1987, 1997; Larsen, Teaford, and Sanford, 1998; Liu et al., 2010; Lukacs and Pastor, 1988; Miao, Tao, Congcang, Wu, and Changsui, 2013; Pechenkina et al., 2002; Saul and Saul, 1991; Saul and Saul, 1997) and has been observed more recently among contemporary living foragers (Berbesque et al., 2012). Berbesque and colleagues (2012:279) observed higher proportions of LSAMAT among Hadza women who often used their front teeth to peel the tough skin from tubers; partially corroborating Turner and Machado's speculations concerning the etiology of the condition among prehistoric groups. They document that tubers are available year-round and are an important part of the diet, making up $26.4 \%$ of the in-camp diet among women and $13.8 \%$ among men, a sex difference of approximately $2: 1$. They also identify a direct relationship with the greater consumption of tubers and the higher prevalence of LSAMAT among Hadza women. It is suggestive that the occurrence of LSAMAT in the SMP sample is similarly biased by sex in favor of females ( 3 females: 1 male) though the sample size is too small to assign a gendered pattern to LSAMAT conclusively. 
As with the SMP sample, in most other observations of LSAMAT, the lower teeth do not exhibit concomitant angled occlusal surface wear indicating that the materials being processed were held against the upper teeth (Larsen, 2015). The major difference between the LSAMAT observed in the SMP sample and many of the other documented archaeological cases is the near complete absence of caries. The high fiber tubers native to the Altiplano, and available to the Hadza, stand in stark contrast to the sugary tropical tubers, such as manioc, that likely contributed significantly to the high caries rates observed in several of the archaeological samples (Irish and Turner, 1987; Larsen et al., 1998; Saul and Saul, 1991; Saul and Saul, 1997; Turner and Machado, 1983). The fact that not all cases of LSAMAT are associated with the consumption of tubers (Harper and Fox, 2008; Hartnady and Rose, 1991; Irish and Turner, 1997; Liu et al., 2010; Lukacs and Pastor, 1988) or elevations in caries frequencies (Miao et al., 2013; Pechenkina et al., 2002) highlights the inherent variability in food processing or habitual oral behaviors that contribute to this specialized tooth wear.

The common association of LSAMAT with tuber consumption in the Americas, coupled with observations among the Hadza, provide some support for the suggestion that this type of wear among the SMP sample likely resulted from the foraging and consumption of wild tuber species, which provide staples for much of the indigenous farming seen in the Altiplano today. LSAMAT in the SMP sample could have resulted from using the front teeth to habitually process one or more of the progenitor species of endemic tubers, including potatoes, oca, ulluco, papalisa, or maca. This could have included processing through peeling, shredding, sucking, or grinding for example to reduce one or many of these varied tuber species.

While the wild antecedents may not have contributed to high caries rates during this early period, they may have contributed to the cervical wear on the mandibular anterior teeth of three individuals in the SMP sample. Recession of the gums and resorption of the alveolus - perhaps through tuber processing behaviors or the habitual placement of quids between the lower lip and gums - would have exposed the cervical region of the root to abrasion, perhaps from sand and grit from the peels, and erosion associated with significant changes in oral $\mathrm{pH}$, eventually resulting in localized demineralization of the cementum and dentin. For example, several species of modern endemic tubers, such as bitter varieties of potatoes, contain high levels of alkaloids which are too toxic for consumption without indigenous processing techniques, such as the production of chuño blanco (Woolfe, 1987). The preparation technique utilizes a natural freeze-thaw process followed by trampling to extract the toxins, and can reduce the levels of glycoalkaloids, for example, from $30 \mathrm{mg} / 100 \mathrm{~g}$ in the fresh potato, to about $4 \mathrm{mg} / 100 \mathrm{~g}$ in chuño blanco (Christiansen, 1977). Oral processing techniques such as peeling, sucking, or chewing tubers prior to leaching their toxins could have contributed to cervical wear of the mandibular anterior teeth.

The proposal for tuber processing presented here is also consistent with previous studies that have placed tuber domestication in the south-central Andes. Genetic analyses have suggested that potatoes may have been domesticated from wild species in the south-central Andes, which includes the Titicaca Basin (Spooner, McLean, Ramsay, Waugh, Bryan, 2005). If so, then we would expect to observe archaeological evidence of intensive use of wild progenitor species in the period prior to domestication. Previous analyses at SMP indicate intensive plant processing in the form of substantial investment in ground foods and subterranean storage, providing additional support for a south-central Andean origin. The current study adds new evidence based on dental wear. To be sure, we do not suggest that the very SMP individuals investigated necessarily contributed directly to the domestication process. Nor do we suggest 
that the Titicaca Basin was necessarily the specific geographic locus of tuber domestication. Rather, the evidence more broadly indicates that a key behavioral requisite for domesticationintensive tuber use - is evident in the archaeological record of the south-central Andes. In other words, this analysis, which is the first to observe LSAMAT in Late Archaic period dental wear patterns in the south-central Andes, is broadly consistent with the hypothesis of a south-central Andean origin.

In sum, this study finds that heavy anterior dental wear, relatively flat molar wear planes, and negligible caries in the SMP assemblage are consistent with global samples of terrestrial foragers, who processed and consumed a wide variety of plant and animal resources. The presence of LSAMAT in approximately half of the sample also bolsters the argument that these individuals were processing endemic tubers in the period prior to incipient food production in the south-central Andes.

Acknowledgements. Field research was supported by a National Science Foundation Doctoral Dissertation Improvement Grant (award BCS-1311626), an American Philosophical Society Lewis and Clark Fund for Exploration and Field Research, and The University of Arizona.

\section{LITERATURE CITED}

Aldenderfer, M. S. (1989a). Archaic period 'complementarity' in the Osmore drainage. In D. Rice, C. Stanish, \& P. Scarr, (Eds.), Ecology, settlement, and history in the Osmore drainage, Peru. BAR International Series 545 (pp 101-128). Oxford: England.

Aldenderfer, M. S. (1989b). Archaic period in the south-central Andes. Journal of World Prehistory, 3, 117-58.

Aldenderfer, M. S. (2005). Preludes to power in the highland late Preceramic period. Archeological Papers of the American Anthropological Association, 14, 13-35.

Bandy, M. S. (2006). Early village society in the Formative period in the southern Lake Titicaca basin. Andean Archaeology, 3, 210-236.

Berbesque, J. C, Marlow, F. W., Pawn, I., Thompson, P., Johnson, G., \& Mabulla, A. (2012). Sex differences in Hadza dental wear patterns. Human Nature, 23, 270-282.

Brothwell, D. R. (1989). The relationship of tooth wear to aging. In M. Iscan (Ed.), Age markers in the human skeleton (pp. 303- 318). Springfield, IL: Charles C. Thomas.

Browman, D. L. (1981). New light on Andean Tiwanaku: A detailed reconstruction of Tiwanaku's early commercial and religious empire illuminates the processes by which states evolve. American Scientist, 69, 408-419.

Bruno, M. C. (2006). A morphological approach to documenting the domestication of Chenopodium in the Andes. In M. Zeder, D. Bradley, E. Emshwiller, \& B. Smith (Eds.), Documenting domestication new genetic and archaeological paradigms (pp. 32-45). Berkeley, CA: University of California Press. 
Buikstra, J. E., \& Ubelaker, D. H. (Eds). (1994). Standards for data collection from human skeletal remains. Fayetteville, AR: Archeological Arkansas Archeological Survey Research Series No. 44.

Chattah, N. L., Smith, P. (2006). Variation in occlusal dental wear of two Chalcolithic populations in the southern Levant. American Journal of Physical Anthropology, 130, 471-479.

Christiansen, J. (1977). The utilization of bitter potatoes to improve food production in the high altitude of the tropics (Unpublished doctoral dissertation). Cornell University, New York.

Cipolla, L. M. (2005). Preceramic period settlement patterns in the Huancané-Putina River valley, northern Titicaca basin, Peru. In C. Stanish, A. Cohen, \& M. Aldenderfer (Eds), Advances in Titicaca basin archaeology-1 (pp. 55-64). Los Angeles, CA: Cotsen Institute of Archaeology at UCLA.

Clement, A. F., \& Hillson, S. W. (2012). Intrapopulation variation in macro tooth wear patterns - a case study from Igloolik, Canada. American Journal of Physical Anthropology, 149, 517-524.

Clement, A. F., Hillson, S. W., \& Aiello, L. C. (2012). Tooth wear, Neanderthal facial morphology and the anterior dental loading hypothesis. Journal of Human Evolution, 62, 367376.

Cohen, M. N., \& Armelagos, G. J. (1984). Paleopathology at the origins of agriculture. Orlando, FL: Academic Press.

Craig, N. (2011). Cultural dynamics, climate, and landscape in the south-central Andes during the mid-late Holocene: A consideration of two socio-natural perspectives. Chungará, 43, 367391.

Da-Gloria, P., \& Larsen, C. S. (2014). Oral health of the Paleoamericans of Lagoa Santa, central Brazil. American Journal of Physical Anthropology, 154(1), 11-26.

Deter, C. A. (2009). Gradients of occlusal wear in hunter-gatherers and agriculturalists. American Journal of Physical Anthropology, 138, 247-254.

Eisentraut, P. J. (1998). Macrobotanical remains from southern Peru: A comparison of Late Archaic-Early Formative period sites from the Puna and Suni zones of the western Titicaca Basin. Available from:

http://search.proquest.com/pqdtft/docview/304416915/abstract/13D23DE4B7B65FFD638/1?acc ountid $=8360$

Eshed, V., Gopher, A., \& Hershkovitz, I. (2006). Tooth wear and dental pathology at the advent of agriculture: new evidence from the Levant. American Journal of Physical Anthropology, 130, 145-159.

Fujita, H., \& Ogura, M. (2009). Degree of dental attrition with sex and aging among Jamon and Edo people in Japan. Journal of Oral Biosciences, 51(3), 165-171.

Gill, J. (2001). General linear models: A unified approach. Thousand Oaks, CA: Sage Publications.

Harper, N. K., \& Fox, S. C. (2008). Recent research in Cypriot bioarchaeology. Bioarchaeology of the Near East, 2, 1-38. 
Harryparsad, A., Rahman, L., \& Bunn, B. K. (2013). Amelogenesis imperfecta: a diagnostic and pathological review with case illustration. South African Dental Journal, 68(9), 404-407.

Hartnady, P., \& Rose, J. C. 1991. Abnormal tooth-loss patterns among Archaic-period inhabitants of the lower Pecos region, Texas. In M. Kelley \& C. S. Larsen (Eds.), Advances in dental anthropology (pp. 267-278). New York: Wiley-Liss.

Hastorf, C. A. (2008). The Formative period in the Titicaca basin. In H. Silverman, \& I. Isbell (Eds.), Handbook of South American Archaeology (pp. 545-561). New York: Springer.

Hillson, S. (2002). Dental anthropology (third edition). Cambridge, England: Cambridge University Press.

Haas, W. R. J., \& Viviano Llave, C. A. (2015). Lake Titicaca Basin foragers on the eve of agriculture: Insights from Soro Mik'aya Patjxa, Peru, 8000-6700 B.P. Antiquity, 89(348), 1297 1312.

Irish, J. D., \& Turner II, C. G. (1987). More lingual surface attrition of the maxillary anterior teeth in American Indians: Prehistoric Panamanians. American Journal of Physical Anthropology, 73(1), 209-213.

Irish, J. D., \& Turner II, C. G. (1997). First evidence of LSAMAT in non-Native Americans: Historic Senegalese from West Africa. American Journal of Physical Anthropology, 102(1), 141146.

Janusek, J. W. (2004). Tiwanaku and its precursors recent research and emerging perspectives. Journal of Archaeological Research, 12, 121-183.

Juengst, S. L, Chávez, S. J, Hutchinson, D. L., \& Chávez, S. R. (2016). Late preceramic foragerherders from the Copacabana Peninsula in the Titicaca Basin of Bolivia: A bioarchaeological analysis. International Journal of Osteoarchaeology (in press) doi: 10.1002/oa.2566.

Kaidonis, J. A. (2008). Tooth wear: the view of the anthropologist. Clinical Oral Investigation, 12(Suppl 1), 21-26.

Kaidonis, J. A., Ranjitkar, S., Lekkas, D., Brook, A. H., \& Townsend, G. C. (2014). Functional dental occlusion: an anthropological perspective and implications for practice. Australian Dental Journal, 59(1 Suppl), 1-12.

Kaidonis, J. A., Richards, L. C., Townsend, G. C., \& Tansley, G. D. (1988). Wear of human enamel: a quantitative in vitro assessment. Journal of Dental Research, 77, 1983-1990.

Kaifu, Y. (1999). Changes in the pattern of tooth wear from prehistoric to recent period in Japan. American Journal of Physical Anthropology, 109, 485-499.

Kieser, J. S., Dennison, K. J., Kaidonis, J. A., Huang, D., Herbison, P. G. P., \& Tayles, N. G. 2001. Patterns of dental wear in the early Maori dentition. International Journal of Osteoarchaeology, 11, 206-217.

Klink, C. J. (2005). Archaic Period research in the Río Huenque Valley, Peru. In C. Stanish, A. Cohen, \& M. Aldenderfer (Eds.), Advances in Titicaca basin archaeology-1 (pp. 13-24). Los Angeles, CA: Cotsen Institute of Archaeology at UCLA.

Kolata, A. L. (1993). The Tiwanaku: Portrait of an Andean civilization. Cambridge, MA: Blackwell. 
La Favre, K. (2011). Limiting population size in hunter-gatherer societies: An analysis of projectile points from the Lake Titicaca Basin, Perú. (Unpublished master's thesis), University of California, Los Angeles.

Larsen, C. S. (1981). Skeletal and dental adaptations to the shift to agriculture on the Georgia coast population. Current Anthropology, 22, 422-423.

Larsen, C. S. (2015). Bioarchaeology. Interpreting behavior from the human skeleton (second edition). Cambridge: Cambridge University Press.

Larsen, C. S., Teaford, M. F., \& Sanford, M. K. (1998). Teeth as tools at Tutu: extramasticatory behavior in prehistoric St. Thomas, U.S. Virgin Islands. In J. Lukacs (Ed.), Human dental development, morphology, and pathology (pp. 401-420). Eugene, OR: University of Oregon Press.

Lanfranco, L. P., \& Eggers, S. (2010). The usefulness of caries frequency, depth, and location in determining cariogenicity and past subsistence: A test on early and later agriculturalists from the Peruvian coast. American Journal of Physical Anthropology, 143, 75-91.

Littleton, J., \& Frohlich, B. (1993). Fish eaters and farmers: dental pathology in the Arabian Gulf. American Journal of Physical Anthropology, 92(4), 427-447.

Littleton, J., Scott, R., McFarlane, G., \& Walshe, K. (2013). Hunter-Gatherer Variability: Dental Wear in South Australia. American Journal of Physical Anthropology, 152, 273-286.

Liu, W., Zhang, Q. C., Wu, X., \& Zhu, H. (2010). Tooth wear and dental pathology of the Bronze-Iron age people in Xinjiang, northwest China: Implications for their diet and lifestyle. Homo, 61(2), 102-116.

Lovejoy, C. O. (1985). Dental wear in the Libben population: Its functional pattern and role in the determination of adult skeletal age at death. American Journal of Physical Anthropology, 68, 47-56.

Lucas, P. W., Omar, R., Al-Fadhalah, K., Almusallam, A. S., Henry, A. G., Michael, S., Thai, L. A., Watzke, J., Strait, D. S., \& Atkins, A. G. (2013). Mechanisms and causes of wear in tooth enamel: implications for hominin diets. Journal of The Royal Society Interface, 80, 20120923.

Lukacs, J. R. (1992). Dental paleopathology and agricultural intensification in south Asia: new evidence from Bronze Age Harappa. American Journal of Physical Anthropology, 87(1), 133150.

Lukacs, J. R. (2008). Fertility and agriculture accentuate sex differences in dental caries rates. Current Anthropology, 49(5), 901-914.

Lukacs, J. R., \& Pastor, R. F. (1988). Activity-induced patterns of dental abrasion in prehistoric Pakistan: Evidence from Mehrgarh and Harappa. American Journal of Physical Anthropology, 76(3), 377-398.

Mayhall, J. T., \& Kanazawa, E. (1989). Three-dimensional analysis of the maxillary first molar crowns of Canadian Inuit. American Journal of Physical Anthropology, 78, 73-78.

Miao, W., Tao, W., Congcang, Z., Wu, L., \& Changsui, W. (2013). Dental wear and oral health as indicators of diet among the early Qin people: A case study from the Xishan site, Gansu 
Province. In K. Pechenkina \& M. Oxenham (Eds.), Bioarchaeology of East Asia: Movement, Contact, Health. Gainesville, FL: University Press of Florida.

Miles, A. E. W. (2001). The Miles method of assessing age from tooth wear revisited. Journal of Archaeological Science, 28, 973-982.

Milner, G. R., \& Larsen, C. S. (1991). Teeth as artifacts of human behavior: intentional mutilation and accidental modification. In M. Kelley \& C. S. Larsen (Eds.), Advances in dental anthropology (pp. 357-378). New York: Wiley-Liss.

Mølleson, T., Jones, K., \& Jones, S. (1993). Dietary change and the effects of food preparation on microwear patterns in the late Neolithic of Abu Hureyra, northern Syria. Journal of Human Evolution, 24, 455-468.

Molnar, P. (2008). Dental wear and oral pathology: Possible evidence and consequences of habitual use of teeth in a Swedish Neolithic sample. American Journal of Physical Anthropology, 136(4), 423-431.

Molnar, S. (1971). Human tooth wear, tooth function, and cultural variability. American Journal of Physical Anthropology, 34, 175-190.

Molnar, S., \& Molnar, I. (1990). Dental arch shape and tooth wear variability. American Journal of Physical Anthropology, 82, 385-395.

Moore, W. J., \& Corbett, M. E. (1971). The distribution of dental caries in ancient British populations 1: Anglo-Saxon period. Caries Research, 5, 151-168.

Osborn, J. W. (1984). Helicoidal plane of dental occlusion. American Journal of Physical Anthropology, 57, 273-281.

Pearsall, D. M. (1992). The origins of plant cultivation in South America. In C. Cowan, P. Watson, \& N. Benco (Eds.), The origins of agriculture: An international perspective (pp. 173205). Washington, D.C.: Smithsonian Institution Press.

Pechenkina, E. A., Benfer, R. A., \& Zhijun, W. (2002). Diet and health changes at the end of the Chinese Neolithic: The Yangshao/Longshan transition in Shaanxi province. American Journal of Physical Anthropology, 117, 15-36.

Price, T. D., \& Gebauer, A. B. (Eds.). (1995). Last hunters, first farmers: New perspectives on the prehistoric transition to agriculture (first edition). Santa Fe, NM: School of American Research Press.

Reinhardt, G. A. (1983). Attrition and edge-to-edge bite. An anthropological study. The Angle Orthodontist, 53(2), 157-164.

Rumold, C. U., \& Aldenderfer, M. S. (2016). Late Archaic-Early Formative period microbotanical evidence for potato at Jiskairumoko in the Titicaca Basin of southern Peru. Proceedings of the National Academy of Sciences, 113, 13672-13677.

Saul, F. P., \& Saul, J. M. (1991). The Preclassic population of Cuello. In N. Hammond (Ed.), Cuello: An early Maya community in Belize (pp. 134-158). Cambridge, England: Cambridge University Press. 
Saul, J. M., \& Saul, F. P. (1997). The Preclassic skeletons from Cuello. In S. Whittington \& D. Reed (Eds.), Bones of the Maya: Studies of ancient skeletons (pp. 28-50). Washington, DC: Smithsonian Institution Press.

Sciulli, P. W. (1997). Dental evolution in prehistoric Native Americans of the Ohio Valley Area. I. Wear and pathology. International Journal of Osteoarchaeology, 7, 507-524.

Scott, E. C. (1979a). Dental wear scoring technique. American Journal of Physical Anthropology, 51, 213-218.

Scott, E. C. (1979b). Principal axis analysis of dental attrition data. American Journal of Physical Anthropology, 51, 203-212.

Scott, R. G., \& Winn, J. R. (2011). Dental chipping: Contrasting patterns of microtrauma in Inuit and European populations. International Journal of Osteoarchaeology, 21, 723-731.

Smith, B. D. (1995). The emergence of agriculture. New York, NY: Scientific American Library.

Smith, B. H. (1984). Patterns of molar wear in hunter-gatherer and agriculturalists. American Journal of Physical Anthropology, 63, 39-56.

Smith, P. (1972). Diet and attrition in the Natufians. American Journal of Physical Anthropology, 37, 233-238.

Spooner, D. M., McLean, K., Ramsay, G., Waugh, R., \& Bryan, G. J. (2005). A single domestication for potato based on multilocus amplified fragment length polymorphism genotyping. Proceedings of the National Academy of Sciences, 102(41), 14694-14699.

Stanish, C. (2001). The origin of state societies in South America. Annual Review of Anthropology, 30, 41-64.

Stanish, C. (2003). Ancient Titicaca: The evolution of complex society in southern Peru and northern Bolivia. Berkeley, CA: University of California Press.

Taylor, R. M. S. (1963). Cause and effect of wear of teeth: Further nonmetrical studies of the teeth and palate in Moriori and Maori skulls. Acta Anatomica, 53, 97-157.

Turner II, C. G. (1979). Dental anthropological indications of agriculture among the Jamon people of central Japan. American Journal of Physical Anthropology, 51, 619-635.

Turner II, C. G, \& Machado, L. M. C. (1983). A new dental wear pattern and evidence for high carbohydrate consumption in a Brazilian Archaic skeletal population. American Journal of Physical Anthropology, 61, 125-130.

Ubelaker, D. H. (1989). Human skeletal remains: Excavation, analysis, interpretation (second edition). Washington, D.C.: Taraxacum.

Walker, P. L., \& Erlandson, J. M. (1986). Dental evidence for prehistoric dietary change on the Northern Channel Islands, California. American Antiquity, 51(2), 357-383.

Watson, J. T. (2008). Changes in food processing and occlusal dental wear during the Early Agricultural period in northwest Mexico. American Journal of Physical Anthropology, 135, 92 99. 
Watson, J. T., Arriaza, B. T., Standen, V., Munoz Ovalle, I. (2013). Tooth wear related to marine foraging, agro-pastoralism and the formative transition on the northern Chilean coast.

International Journal of Osteoarchaeolgy, 23(3), 287-302.

Woolfe, J. A. (1987). The Potato in the Human Diet. Cambridge, England: Cambridge University Press. 


\section{FIGURE LEGEND}

FIGURE 1. Chronogram (left) and map (right) illustrating the temporal and spatial locations of Soro Mik'aya Patjxa (SMP) and other important Archaic period sites in the south-central Andean highlands.

FIGURE 2. Image of burials recovered from the Soro Mik'aya Patjxa site.

FIGURE 3. Plot of mean wear scores for polar teeth (I1, C, P1, M1) across age categories (top: maxillary teeth; bottom: mandibular teeth).

FIGURE 4. Box plots of standardized wear scores in the Soro Mik'aya Patjxa sample across both upper (left side) and lower (right side) dental arcades - the first molar (not included) is the reference tooth for these scores and is represented by a dashed line passing through 100 on the $y$ axis. The top and bottom of each box represent the upper and lower quartile values, the bar inside each box represents the median, and the upper and lower lines represent the overall range of values.

FIGURE 5. Scatterplots of molar wear rate (top) and molar wear angle (bottom) for the Soro Mik'aya Patjxa sample; shown with regression lines.

FIGURE 6. Scatterplot of slope (b) and y-intercept values from results of principle axis analyses for samples of foragers from Soro Mik'aya Patjxa (SMP) and northwest Chile (CHN), mixed subsistence groups from northwest Mexico (LPA) and northwest Chile (AZP), and farmers from the Levantine Chalcolithic (LC1 and LC2). Lines display 95\% CI for slope.

FIGURE 7. LSAMAT observed in Burial 7, a young adult female from Soro Mik'aya Patjxa (top). Cervical wear on the mandibular anterior teeth observed along lingual-proximal root surfaces (bottom). 